\title{
Kinerja Aparatur Pemerintahan Daerah Kabupaten Batanghari
}

\author{
Etty Siswati $^{1 *}$, Sumantri ${ }^{2}$, Albetris ${ }^{3}$, Aris Triyono ${ }^{4}$ \\ ${ }^{1,2}$ STIE Graha Karya Muara Bulian \\ ${ }^{3}$ Universitas Batanghari Jambi \\ ${ }^{4}$ STIE Indragiri Rengat \\ *Correspondence email: ettysiswati793@gmail.com, Sumantri.baharun123@gmail.com, \\ albetris90@gmail.com, arist@stieindragiri.ac.id
}

\begin{abstract}
Abstrak. Tujuan Penulis membuat Penelitian ini adalah untuk melihat seberapa besar pengaruh variabel independen yang terdiri dari Partisipasi (X1), Motivasi (X2) dan Pelimpahan Wewenang (X3) Terhadap variabel Dependen yaitu Kinerja (Y) Aparatur Pemerintahan di Kabupaet Batanghari Jambi. Penelitian ini Dikategorikan kedalam penelitian yang bersifat deskriptif kuantitatif dan Sampel dari penelitian ini sebanyak 104 Responden. Metode pengumpulan data yaitu Stratified random smpling dengan alokasi 2 responden setiap strata. Dari penelitian yang telah penulis lakukan maka di dapat hasil dari Uji parsial untuk nilai (X1) t - hitung 1.734 lebih besar dibandingkan degan t - tabel yaitu 1.66025, (X2) dengan nilai t - hitung 0,421 lebih kecil dari nilai t tabel yaitu sebesar 1.66025, Sedangkan (X3) nilai t - hitung 1.570 lebih kecil dari pada nilai $\mathrm{t}$ - tabel 1.66025. sedangkan hasil Uji Simultan (Uji F) didapati nilai F - hitung dengan nilai sebesar 4.789 dan nilai F - tabel dengan nilai sebesar 2,70 karena nilai F hitung lebih besar $\mathrm{F}$ - tabel, maka penulis menyimpulkan bahwa Partisipasi, Motivasi, Pelimpahan Wewenang menunjukan pengaruh yang signifikan dan Positif terhadap kinerja Aparatur Pemerintahan. Dan dari Hasil Adjusted R Square di dapati nilai 0.99, Penulis menyimpulkan pengaruh Partisipasi(X1), Motivasi(X2), Pelimpahan wewenang (X3) terhadap Kinerja Aparatur Pemerintahan (Y) sebesar 9.9\% dan 90,1\% dipengaruhi oleh variabel yang belum di masukkan dalam penelitian ini.
\end{abstract}

Kata Kunci: Partisipasi; Motivasi; Pelimpahan Wewenang; Kinerja

Abstract. The purpose of the Author to make this study is to see how much influence independent variables consisting of Participation (X1), Motivation (X2) and Delegation of Authority (X3) To dependent variables namely Performance (Y) Government Apparatus in Batanghari Jambi District. This research is categorized into descriptive quantitative research and samples from this study as many as 104 respondents. Data collection method is Stratified random smpling with the allocation of 2 respondents per strata. From the research that the authors have done, the results of the partial test for the value (X1) $t$ - count 1,734 greater than degan $t$ - table that is 1.66025, (X2) with a value of $t$ - count 0.421 less than the value of $t$ - table is 1.66025 , while (X3) the value $t$ - count 1570 is smaller than the value $t$ - table 1.66025. while the results of simultaneous test (Test $F$ ) were found to be $F$ - calculated with a value of 4,789 and a value of $F$ - a table with a value of 2.70 because the value of $F$ - count greater F - table, then the author concluded that Participation, Motivation, Delegation of Authority showed a significant and Positive influence on the performance of government apparatus. And from the Results adjusted $R$ Square obtained a value of 0.99 , the author concluded the influence of Participation(X1), Motivation(X2), Delegation of authority (X3) to the Performance of Government Apparatus (Y) by $9.9 \%$ and $90.1 \%$ influenced by variables that have not been included in this study.

Keywords: Participation; Motivation; Delegation of Authority; Performance

\section{PENDAHULUAN}

Pada sektor swasta anggaran ialah bagian dari rahasia perusahaan yang tertutup buat publik, tetapi kebalikannya pada sektor publik anggaran adalah Kewajiban yang harus diinformasikan pada publik Agar bisa dikritik serta didiskusikan buat menemukan masukan. Anggaran sektor publik ialah instrumen akuntabilitas atas pengurusan anggaran publik serta penerapan program - program yang dibiayai dari duit public (FAUZAN, 2020). Penganggaran sektor public (Hidayah \& Haryono, 2015) terpaut dalam cara determinasi jumlah peruntukan anggaran Pada masingmasing program, serta kegiatan dalam dasar moneter.

Penganggaran Didaerah diatur dalam peraturan (Menteri, 2007). Regulasi, ini menerangkan mengenai prinsip dalam konsep anggaran pemasukan serta berbelanja didaerah yang dilaksanakan oleh tim anggaran bersama dengan badan Organisasi di tingkat daerah. Konsep anggaran Merupakan kegiatan yang termasuk kedalam suatu konsep yang di sebut sebagai Rancangan anggaran Satuan Kerja (RASK). RASK Berisikan standar analisa berbelanja, Parameter kemampuan serta standar yang dijadikan intrumen utama dalam anggaran Kinerja.

Anggaran pada sektor Pemerintah (Djaja, 2015) terpaut dengan cara penentuan jumlah peruntukan anggaran di tiap program serta kegiatan yang dipakai dalam tiap program itu sendiri, anggaran Tersebut berasal dari masyarakat (Menpan, 2013). Dalam perihal inilah terjalin perbandingan antara anggaran sektor publik serta anggaran sektor swasta. Pada anggaran sektor publik anggaran yang sudah disusun diterbitkan agar bisa di lihat oleh seluruh masyarakat, dimana anggaran dari sektor publik berawal dari pajak, pungutan (Retribusi), keuntungan perusahaan milik daerah, pinjaman Pemerintah yang berbentuk pinjaman luar 
negeri serta surat pinjaman (obligasi). Sebaliknya dalam sektor swasta anggaran yang sudah disusun tidak hendak diterbitkan pada Masyarakat disebabkan anggaran itu adalah rahasia Perusahaan. Anggaran dari sektor swasta berawal dari modal sendiri, keuntungan ditahan, aktiva serta pembiayaan ekternal yang mencakup pinjaman bank, surat pinjaman (Obligasi), publikasi saham.

Perhitungan sektor publik (Syachbrani \& Baharuddin, 2019) memiliki kegunaan yang sangat penting seperti perlengkapan pemograman, perlengkapan pengaturan, perlengkapan kebijaksanaan pajak, perlengkapan politik, perlengkapan koordinasi serta komunikasi, perlengkapan evaluasi kemampuan, perlengkapan dorongan, serta perlengkapan invensi ruang publik. (Anwar et al., 2012) mendefinisikan pemakaian perhitungan anggaran bisa dipergunakan selaku perlengkapan untuk mendelegasikan wewenang pimpinan pada anak buah.

Pemakaian perhitungan anggaran (Djaja, 2015) itu sendiri hendak menimbulkan bermacam sikap berperilaku seseorang dalam perihal pengaturan dan mengendalikan, mengevaluasi hasil kerja, serta berkoordinasi. Pemakaian perhitungan Anggaran bisa dilaksanakan dengan sangat baik jika perhitungan yang telah di buat di jalankan dengan baik oleh orang yang dilimpakan wewenang, wewenang dari pimpinan pada anak buah (Pegawainya). Pemakaian perhitungan Anggaran hendaknya cocok dengan target bila cara langkah perhitungan yang dibuat sudah cocok dengan apa yang dingiinkan dan dibutuhkan oleh pegawai.

(Hansen, 1997) menarangkan Jika cara pengkategorian perhitungan anggaran memotivasi seluruh manager buat memperjelas arah organisasi, meramalkan apa saja hal yang di anggap mempersulit, serta meningkatkan dan membuat kebijakan kedepan. dilain sisi jika cara pengkategorian perhitungan anggaran ialah aktivitas yang berarti terhadap lingkungan, sebab perhitungan memiliki akibat fungsional serta disfungsional kepada tindakan serta sikap semua aspek di organisasi, sebaliknya metode agar terhindar dari terbentuknya akibat disfungsional anggaran yang ada maka diwajibkan kepada anak buah untuk berdiskusi tentang bagaimana membuat suatu anggaran.

Kesertaan dalam menyusun anggaran (Galbraith, n.d.) sangat dekat hubungannya dengan kemampuan petugas pemerintah didaerah, sebab kemampuan petugas pemerintah didaerah diamati dari kesertaan petugas pemerintah itu sendiri dalam penyusunan perhitungan anggaran. Pimpinan Badan Pemeriksa Keuangan (BPK), Nasution melaporkan Jika hasil audit yang dilakukan oleh BPK tentang kemampuan Pemerintahan di Indonesia jauh dari standar yang sudah ditetapkan (Prasetyo, 2019).

Dengan desakan Pemerintahan daerah yang turut serta dalam proses penganganggaran, dalam hal ini dibutuhkan komunikasi antara pimpinan serta anak buah agar bisa saling bertukar informasi secara lokal, sebab anak buah lebih mengenali situasi langsung yang terjadi pada bagiannya. Dari keempat aspek itu jika dilakukan maka reinventing lokal government dengan metode menilai kemampuan Pemerintah didaerah akan terbarukan (Abidin, 2015).

Pada saat dipimpin oleh Bupati H. Abdul Fattah,

SH, Pemerintah Kabupaten Batanghari telah mengimplementasi pelaksanaan akuntabilitas kinerja pada lingkungan pemerintah daerah untuk mewujudkan pemerintahan yang fokus kepada Hasil, (Dwi et al., 2019) dengan melaksanakan PP No.8 Tahun 2006 tentang Pelaporan Keuangan dan Kinerja Instansi Pemerintah (Permenpan, 2014), (MenpanRB, 2012) Inpres No. 7 Tahun 1999 tentang Akuntabilitas Kinerja Instansi Pemerintah, Keputusan Menteri Pendayagunaan Aparatur Negara dan Reformasi Birokrasi No. KEP135/M.PAN/9/2004 tentang Pedoman Umum Evaluasi LAKIP (Permenpan, 2014), dan Peraturan MenPAN dan RB No. 35 Tahun 2011 tentang Petunjuk Pelaksanaan Evaluasi Akuntabilitas Kinerja Instansi Pemerintah Tahun 2011(MenpanRB, 2012), Kepmen PAN dan RB pada Tahun 2011 telah melakukan evaluasi akuntabilitas kinerja terhadap Pemerintah Provinsi dan Kabupaten/ Kota yang menyerahkan LAKIT tepat waktunya. Pemkab Batanghari berhasil meraih Penghargaan Sistim Akuntablitas kinerja Instenasi Pemerintah tahun 2010 dari Menteri Pendayagunaan Aparatur Negara dan Reformasi Birokrasi RI : E.E. Mangindaan di Jakarta 7 februari 2011 lalu Bidang Pengawasan dan Akuntabilitas Aparatur, Jakarta.

Kesuksesan itu terjadi diawal tahun 2012 dengan terpilihnya kembali Pemkab Batanghari Sebaga penerima penghargaan Laporan Hasil Evaluasi Akuntabilitas Kinerja Pemerintah Provinsi dan Kabupatan/Kota Tahun 2011 Prediket CC dengan nilai Baik yang penyerahannya dilakukan MenPANRB RI (http://batangharikab.go.id/bat/publikasi-571-pemkabbatang-hari-raih-penghargaan-terbaik-sistemakuntabilitas-instansi-pemerintah.html).

Pemkab Batanghari bisa mencapai hasil ini merupakan penilaian KemenPANRB dalam penilaian Pemkab Batanghari yang yelah sukses mempraktikkan sistem Pelaksanaan Evaluasi Akuntabilitas Kinerja Instansi Pemerintah pada Tahun 2011 yang mencakup Pemograman Kerja yang terencana, Pengukuran, Laporan serta Penilaian dan Capaian Pekerjaan yang merupakan evaluasi kepada semua bagian manajemen kinerja lingkungan Pemerintah Kabupaten Batanghari.

Bupati H. Abdul Fattah menarangkan, kesuksesan Pemkab Batanghari mencapai apresiasi ini merupakan berkah serta kesertaan yang aktif dari semua Lembaga yang ada di kabupaten Batanghari dalam menangani Laporan Akuntabilitas Kinerja Instansi Pemerintah, ini merupakan kesuksesan kita bersama semua SKPD yang bertugas dengan mematuhi ketentuan serta determinasi yang legal, selanjutnya Bupati menginginkan pada para Kepala SKPD supaya menjaga hasil yang telah kita 
capai, dengan meningkatkan kemampuan serta sistem Pelaporan sesuai dengan Tupoksi yang di tentukan, ketentuan serta determinasi yang legal, agar kedepan kita tidak cuma menjaga hasil yang telah di capai ini ini, tetapi sanggup mencapai hasil yang lebih besar.

\section{METODE}

\section{Objek Penelitian}

metode penelitian yang di pakai oleh penulis adalah Metode survey, Metode ini adalah untuk mendapatkan penilaian dari responden dengan penggunaan kuesioner, kuesioner ini dipakai penulis baik agara bisa sesuai dengan kebutuhan baik secara struktur dan pola pertanyaannya, dengan harapan akan didapat data yang cukup reprensentatif untuk menjelaskan apa yang di teliti penulis (Thakkar, 2013).

Metode penelitian yang dipakai oleh penulis adalah metode Kualitatif analisis yaitu dengan menganalisis fenomena apa saja yang telah terjadi agar bisa menjelaskan hubungan antar variabel, juga untuk membuktikan dugaan yang di bangun peneliti berdasarkan data yang diperoleh agar di dapatkan hasil yang akurat dari suatu masalah yang ingin diselesaikan oleh penulis (Nazir et al., 2013).

\section{Populasi dan Sampel Populasi}

Populasi (Blunch, 2012) didalam penelitian ini meliputi semua Kepala SKPD di Kabupaten Batanghari Jambi, Sampel yang digunakan dipenelitian ini yaitu kepala Kesatuan Kerja Perangkat Daerah (SKPD) juga kepala bagian yang ada di sekretaris dan dinas didaerah juga lembaga teknis didaerah yang ada di Kabupaten Batanghari. Jumlah populasi sebesar 104 orang.

\section{Sampel}

Baik dari sisi golongan kepangkatan, masa kerja, tingkat pendidikan maupun tingkat pendapatan maka populasi dijadikan sampel atau responden Mengingat populasi heterogen (Ho, 2006). Maka jumlah responden diteliti sama dengan populasi yaitu 104 Responden,

\section{Sumber Data}

\section{Data Primer}

Data primer (Jak, 2015) diambil langsung oleh penulis dari sumbernya ataupun data yang belum melalui proses pengumpulan data dari pihak lain. Dalam penelitian ini, data primer diperoleh dari survei dengan memberikan kuesioner kepada masing-masing kantor/instansi di SKPD kabupaten Batanghari.

\section{Data Sekunder}

Data sekunder (Blunch, 2012) penulis ambil dari studi pustaka dengan mengumpulkan data yang dipakai sebagai landasan teori dengan cara mencari dan menyususn dari berbagai literatur yang terkait mempunyai hubungan yang erat dengan penelitian ini.

\section{Teknik Pengumpulan Data}

Teknik pengumpulan data yang dilakuikan oleh penulis untuk mendapatkan data primer adalah dengan kuisioner (Blunch, 2012). Kuisioner dibentuk dari pertanyaan yang terstruktur agar responden bisa dibatasi untuk memberikan jawaban.

\section{Transformasi Data}

Agar syarat dalam analisis parametrik terpenuhi, data harus berskala interval, maka data yang diperoleh skala likert (data ordinal) agar terdapat kesaman antara ciri fisik yang berjenis kualitatif dengan yang numerik, sebelum data diolah, data terlebih dahulu diberikan kode berupa angka dalam setiap jawaban. Dan data ordinal tersebut diubah menjadi data interval dengan menggunakan Methode of Successive Interval. (Ridwan \& Anik, 2020).

\section{Uji Kualitas Data}

Data tidak berguna jika alat pengukur yang digunakan untuk mengumpulkan data penelitian tersebut tidak memiliki validitas dengan taraf signifikansi 5\% dan reliabilitas yang tinggi. Maka dari itu Keshahihan dan keandalan data perlu diuji supaya menghasilkan kesimpulan yang tidak bias (Ho, 2006).

\section{Uji Validitas dan Realibilitas}

Uji validitas ini dilakukan untuk mengetahui apakah bagian pertanyaan yang ada di kuesioner bisa untuk mewakili apa yang akan diteliti penulis (Giusti et al., 2018). Uji ini menilai setiap item pertanyaan dikorelasikan dengan nilai total seluruh item pertanyaan taraf signifikansinya sebesar 5\% (Hairo \& Martono, 2019). Dengan Aplikasi SPSS, reliabilitas diukur melalui statistik cronbach alfa, dengan syarat variabel dikatakan reliabel jika nilai cronbach alfa > 0,60 (Herlina \& Lestari, 2021).

\section{Uji Asumsi Klasik}

Model yang dapat dikatakan baik adalah apabila model tersebut memenuhi empat Uji asumsi yaitu data berdistribusi normal, tidak terjadi multikolinearitas, tidak terjadi autokorelasi dan terakhir tidak terjadi heteroskedastisitas (Ho, 2006).

\section{Uji Normalitas}

Uji ini mempunyai tujuan untuk melihat model regresi variabel terikat (dependen) dan variabel bebas (independen) memiliki distribusi normal. Untuk mengujinya dilakukan dengan melihat dan membaca analisis grafik dari hasil SPSS. Jika terlihat penyebaran data (titik) mendekati pada sumbu diagonal dari grafik normal probability plot maka data dikatakan normal.

\section{Uji Multikolinieritas}

Uji multikolinieritas bertujuan untuk menguji apakah model regresi ditemukan adanya korelasi antar 
variabel bebas (independen). Uji ini dilihat dengan cara nilai tolerance $\leq 0,10$ atau nilai VIF $\geq 10$ (Blunch, 2012).

\section{Uji Heteroskedastisitas}

Untuk melihat ada atau tidaknya heteroskedastisitas dapat dilakukan dengan melihat grafik Plot antara nilaai prediksi variabel terikat (dependen) dengan nilai residualnya (Blunch, 2012).

\section{Teknik Analisa Data}

Analisis Regresi Linier berganada ini dilakukan untuk mencari kolerasi antara dua atau lebih variabel independen dengan satu variabel dependen dan taraf signifikasinya (Blunch, 2012).

Dari tiga variabel independen dan satu variabel dependen maka di buatlah rumus regresi linier berganda sebagai berikut :

$Y=\alpha+b 1 X 1+b 2 X 2+b 3 X 3+\varepsilon$

Keterangan :

$\mathrm{Y} \quad=$ Kinerja

$\mathrm{X} 1=$ Partisipasi

$\mathrm{X} 2=$ Motivasi

$\mathrm{X} 3=$ Pelimpahan Wewenang

\section{HASIL DAN PEMBAHASAN}

Hasil yang diperoleh dengngan menyebar kuesioner langsung kepada kepala SKPD (Kesatuan Kerja Perangkat Daerah) dan kepala bagian di Pemerintahan Daerah Kabupaten Batanghari. Dari 104 kuisioner pada penelitian ini disebarkan kepada responden, setiap responden menjawab 6 pertanyaan partisipasi penyusunan anggaran, 8 pertanyaan Motivasi penyusunan anggaran, 6 pertanyaan pelimpahan wewenang penyusunan anggaran, 10 pertanyaan kepuasan kerja, 10 pertanyaan kinerja Aparat pemerintahan. Didapati Hasil sebagai berikut :

\section{Uji Validitas}

Hasil Uji Validitas berikut menyajikan hasil uji validitas terhadap item pertanyaan partisipasi(X1), Motivasi(X2), Pelimpahan Wewenang(X3) dan KinerjaY).

Tabel 1. Hasil Uji Validitas Partisipasi (X1) Motivasi (X2), Pelimpahan Wewenang ( X3) Kinerja (Y) degan R tabel

$$
0.190 \text {. }
$$

\begin{tabular}{ccc}
\hline Item Pertanyaan & Korelasi ( r ) & Keterangan \\
\hline & 0,639 & Valid \\
& 0,730 & Valid \\
Variabel Partisipasi (X) & 0,843 & Valid \\
& 0,575 & Valid \\
& 0,577 & Valid \\
& 0,667 & Valid \\
\hline & 0,740 & Valid \\
Variabel Motivasi (X2) & 0,808 & Valid \\
& 0,829 & Valid \\
& 0,837 & Valid
\end{tabular}

\begin{tabular}{ccc}
\hline & 0,813 & Valid \\
& 0,845 & Valid \\
& 0,796 & Valid \\
& 0,744 & Valid \\
\hline & 0,654 & Valid \\
& 0,753 & Valid \\
Pelimpahan Wewenang & 0,767 & Valid \\
(Variabel X3) & 0,738 & Valid \\
& 0,714 & Valid \\
& 0,670 & Valid \\
\hline & 0,608 & Valid \\
& 0,654 & Valid \\
& 0,739 & Valid \\
& 0,664 & Valid \\
& 0,792 & Valid \\
& 0,633 & Valid \\
& 0,597 & Valid \\
& 0,421 & Valid \\
& 0,598 & Valid \\
& 0,456 & Valid \\
\hline
\end{tabular}

Sumber : Hasil Pengolaan Data

\section{Uji Reliabilitas}

Hasil Uji reliabilitas berdasarkan hasil pengujian pada tabel 2 selanjutnya menyajikan hasil reliabilitas terhadap item pertanyaan Partisipasi, Motivasi, pelimpahan wewenang dan, Kinerja

Tabel 2. Hasil Uji Reliability Partisipasi (X1). Motivasi (X2), Pelimpahaan Wewenang (X3), Kinerja (Y)

\begin{tabular}{lcc}
\hline Variabel & Cronbach's Alpha & N of Items \\
\hline Partisipasi $\left(\mathrm{X}_{1}\right)$ & 0,757 & 6 \\
Motivasi $\left(\mathrm{X}_{2}\right)$ & 0,789 & 8 \\
Pelimpahan Wewenang $\left(\mathrm{X}_{3}\right)$ & 0,811 & 6 \\
Kinerja $(\mathrm{Y})$ & 0,820 & 10 \\
\hline
\end{tabular}

Sumber : Data Olah

\section{Uji Asumsi Klasisk}

Uji Normalitas

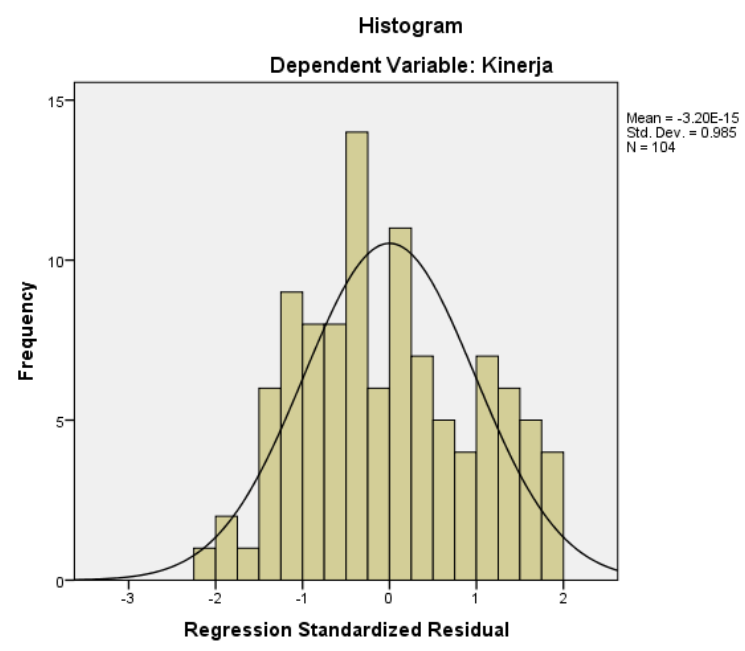

Gambar 1. Grafik histogram 


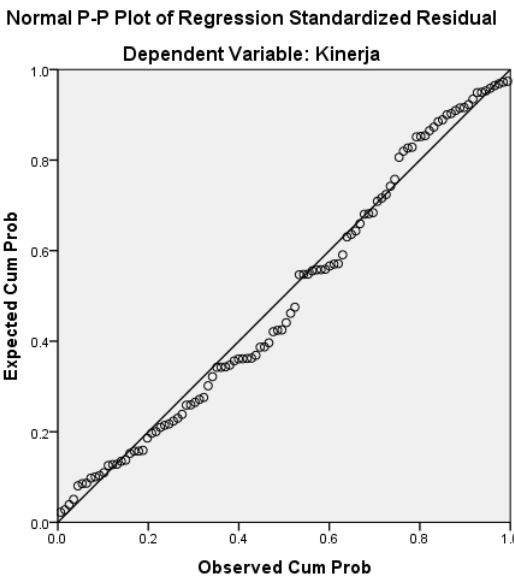

Gambar 2. Grafik P-Plot

Dari gambar diatas yaitu grafik histogram dan grafik P-Plot maka penulis menarik kesimpulan jika pola yang ada dinyatakan berdistribusi normal. Sedangkan pada grafik normal P-Plot juga terlihat bagus. Dari semua gambar tersebut menunjukkan dapat dikatan bahwa model regresi layak diteliti.

\section{Uji Multikolinieritas}

Hasil Program SPSS Uji multikolinieritas bisa di lihat pada tabel 2 dengan variabel Partisipasi(X1), Motivasi (X2), pelimpahan wewenang(X3) dan $\operatorname{Kinerja(Y).~Sebagai~berikut:~}$

Tabel 3. Hasil SPSS Multikolinieritas

\begin{tabular}{lccc}
\hline Variabel Independen & \multicolumn{2}{c}{ Collinearity Statistics } & Keputusan \\
& Tolerance & VIF & \\
\hline Partisipasi & 0,681 & 1.468 & Tidak Terjadi Multikolinieritas \\
Motivasi & 0.859 & 1.164 & Tidak Terjadi Multikolinieritas \\
Pelimpahan Wewenang & 0,629 & 1.589 & Tidak Terjadi Multikolinieritas \\
\hline
\end{tabular}

Sumber: Data Olah

Berdasarkan tabel diatas dapat dilihat bahwa angka tolerance dari variabel independen lebih dari 95 $\%$, Tidak variabel independen yang mempunyai nilai VIF lebih dari 10. Maka dapat penulis simpulkan tidak terjadi multikolinieritas.

\section{Uji Heteroskedastisitas}

Uji ini dilakukan untuk mengetahui kesamaan varian masing-masing variabel independen Partisipasi(X1), Motivasi (X2), pelimpahan

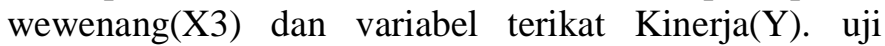
heteroskedastisitas ini melihat grafik plot Regression Standarized Predicted Value dengan Regression Studentized Residual. Hasil pengujian dapat dilihat pada gambar 3 .

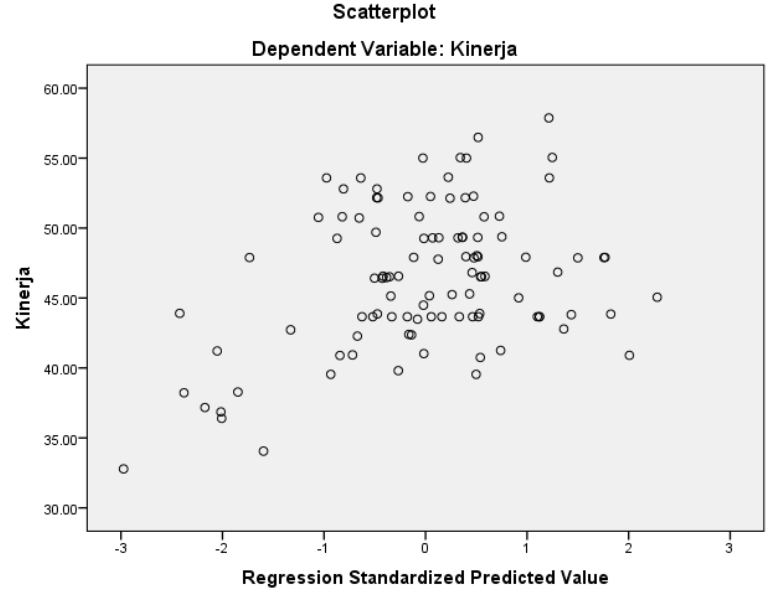

Gambar 3. Grafik Scatterplot

Dari gambar diatas terlihat titik titik menyebar dan tidak membentuk suatu pola, Hal ini mengindikasikan bahwa tidak terjadi heteroskedastisitas dan juga bisa di lihat dari signifikansi semua variabel independen di atas tingkat kepercayaan 0,05.

\section{Analisis Regresi Liner Berganda}

Berdasarkan dari hasil pengolahan data mengunakan Software SPSS 20 dapat diperoleh suatu model regresi liner berganda sebagai berikut :

Tabel 4. Hasil Analisis Regresi Liner Berganda

\begin{tabular}{|c|c|c|c|c|c|}
\hline \multirow{3}{*}{ Model } & \multicolumn{4}{|c|}{ Coefficients $\mathrm{s}^{\mathrm{a}}$} & \multirow{3}{*}{ Sig. } \\
\hline & \multicolumn{2}{|c|}{$\begin{array}{l}\text { Unstandardized } \\
\text { Coefficients }\end{array}$} & $\begin{array}{l}\text { Standardized } \\
\text { Coefficients }\end{array}$ & $\mathrm{t}$ & \\
\hline & B & Std. Error & Beta & & \\
\hline (Constant) & 30.675 & 4.366 & & 7.026 & .000 \\
\hline Partisipasi & .276 & .159 & .196 & 1.734 & .086 \\
\hline Motivasi & .037 & .088 & .042 & .421 & .675 \\
\hline P_Wewenang & .243 & .155 & .185 & 1.570 & .120 \\
\hline
\end{tabular}

Berdasarkan persamaan regresi berganda diatas dapat diintresprestasikan sebagai berikut :

$$
Y=30.675+0,276 X_{1}+0,037 X_{2}+0.243 X_{3}
$$

Nilai Kostanta sebesar 30,675 memberikan arti bahwa apabila partisipasi (X1),motivasi (X2), pelimpahan wewenang $(\mathrm{X} 3)$, diasumsikan $=0$, maka kinerja (Y) secara kostanta bernilai 30,675. Koefisien regresi variabel Partisipasi pemakaian (X1) sebesar 0,276 memberikan arti bahwa dengan penambahan satu satuan partisipasi maka akan terjadi kenaikan kinerja 0,276, dengan asumsi variabel lain tetap. Koefisien regresi variabel motivasi (X2) sebesar 0,037 memberikan arti bahwa dengan penanbahan satu variabel motivasi maka akan terjadi kenaikan 0,037, dengan asumsi variabel lain tetap. Koefisien regresi variabel pelimpahan wewenang 0,243 memberikan arti bahwa dengan penambahan satu variabel pelimpahan 
wewenang maka terjadi kenaikan 0,243,dengan asumsi variabel lain tetap.

\section{Uji F (Uji Simultan)}

\section{Uji Statatistik F (Uji F)}

Dalam penelitian ini di dapati hasil kondisi goodness of fit atau layak (fit) untuk diterpretasikan. Penelitian ini dikatakn memiliki model yang fit dengan data yang dimiliki apabila nilai probalitas singnifikasi < 0,05 diukur dengan Uji ANOVA (Ghazali, 2018). Berikut data yang telah diolah untuk uji $\mathrm{F}$ seperti di bawah ini :

Tabel 5. Hasil Uji Statistik F ANOVA $^{\mathrm{a}}$

\begin{tabular}{lrrrrr}
\hline Model & Sum of Squares & df & Mean Square & F & Sig. \\
\hline Regression & 325.692 & 3 & 108.564 & 4.789 & $.004^{\mathrm{b}}$ \\
Residual & 2266.734 & 100 & 22.667 & & \\
Total & 2592.426 & 103 & & & \\
\hline
\end{tabular}

a. Dependent Variable: Kinerja

b. Predictors: (Constant), Wewenang, Motivasi, Partisipasi

Sumber: Data Olah

Berdasarkan hasil tabel diatas, maka dapat dilihat bahwa nilai singnifikasi lebih kecil 0,05, maka dapat disimpulkan bahwa model dalam penelitian ini layak dan dapat digunakan untuk memprediksi Kinerja Aparatur Pemerintah Daerah Kabupaten Batanghari

\section{Koefisien Determinasi}

Uji ini dilakukan untuk mengukur seberapa peranan variabel partisipasi (X1),motivasi (X2), pelimpahan wewenang (X3), dapat memperjelas varibel dependen yaitu kinerja (Y) Aparatur Pemerintah Daerah Kabupaten Batanghari. Hasil uji koefisien determinasi dapat dilihat dari kolom Adjusted $\mathrm{R}$ Square yang ditampilkan pada table berikut :

\begin{tabular}{|c|c|c|c|c|c|}
\hline \multicolumn{6}{|c|}{$\begin{array}{l}\text { Tabel 6. Uji Detrminasi } \\
\text { Model Summary }^{b}\end{array}$} \\
\hline Model & $\mathrm{R}$ & $\begin{array}{c}R \\
\text { Square }\end{array}$ & $\begin{array}{l}\text { Adjusted R } \\
\text { Square }\end{array}$ & $\begin{array}{l}\text { Std. Error of the } \\
\text { Estimate }\end{array}$ & $\begin{array}{l}\text { Durbin- } \\
\text { Watson }\end{array}$ \\
\hline 1 & $.354^{\mathrm{a}}$ & 126 & .099 & 4.76102 & 1.146 \\
\hline
\end{tabular}

Dari tabel diatas menujukan bahwa kontribusi nilai Adjusted R Square sebesar 0.099 atau 09.9 \%. Hal ini berarti bahwa kontribusi variabel independen yaitu partisipasi (X1),motivasi (X2), pelimpahan wewenang (X3), dapat memperjelas varibel dependen yaitu kinerja (Y) Aparatur Pemerintah Daerah Kabupaten Batanghari 9,9\% sisanya $90,1 \%$ di jelaskan di varibel lain yang tidak diteliti.

\section{Uji Parsial (Uji t)}

Uji statistik t digunkan untuk menguji Pengaruh dari masing-masing variabel independen secara parsial terhadap variabel dependen. Jika nilai sig $<0,05$ maka hiptesis didukung, sedangkan jika nilai sig > 0,05 maka hipotesis tidak didukung (Ghazali 2018). Berikut ini hasil dari uji statistik $\mathrm{t}$ :

Tabel 7. Hasil Uji statistik t

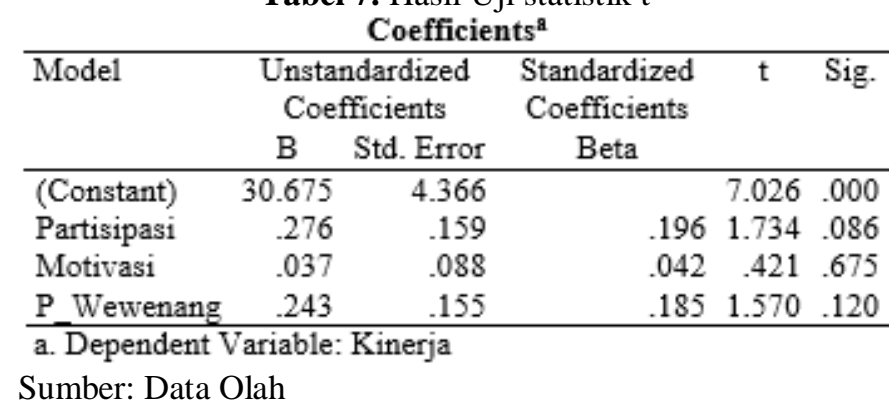

\section{Pembahasan}

Pengaruh Partisipasi terhadap Kinerja Aparatur Pemerintah Daerah Kabupaten Batanghari

1. Nilai koefisien regresi variabel partisipasi (X1). Nilai t-tabel 1.66025 dan nilai thitung 1.734 .

2. Hasil pengujian hipotesis pertama (H1) yang di bangun oleh peneliti menyebutkan bahwa variabel partisipasi berpengaruh positif terhadap kinerja aparatur diterima.

3. Hasil pengujian ini didapati bahwa variabel partisipasi berpengaruh signifikan dan positif terhadap kinerja Aparatur Pemerintah Daerah. dikarenakan nilai thitung 1,734> t-tabel 1,66025 Artinya secara parsial varibel partisipasi berpengaruh terhadap kinerja Aparatur Pemerintah Daerah Kabupaten Batanghari

\section{Pengaruh Motivasi terhadap Kinerja Aparatur} Pemerintah Daerah Kabupaten Batanghari

1. Nilai koefisien regresi variabel motivasi (X2). Nilai ttabel 1.66025 dan nilai thitung 0,421 . Nilai koefisien regresi ini pada tingkat signifikasi sebesar 0,675.

2. Hasil pengujian hipotesis kedua $(\mathrm{H} 2)$ yang di bangun oleh peneliti menyebutkan bahwa motivasi tidak berpengaruh terhadap kinerja Aparatur ditolak.

3. Hasil pengujian ini didapati bahwa variabel motivasi (X2) tidak berpengaruh signifikan terhadap kinerja Aparatur Pemerintah Daerah. dikarenakan nilai thitung $0,420<\mathrm{t}$-tabel 1,66025 . Hasil pengujian ini menginterpretasikan bahwa variabel motivasi tidak berpengaruh terhadap kinerja Aparatur Pemerintah Daerah Kabupaten Batanghari

\section{Pengaruh Pelimpahan Wewenang Kinerja Aparatur Pemerintah Daerah Kabupaten Batanghari}

1. Nilai koefisien regresi variabel pelimpahan wewenang (X3). Nilai t-tabel 1.66025 dan nilai thitung 1.570. Nilai koefisien regresi ini pada tingkat signifikasi sebesar 0,120 .

2. Hasil pengujian Hipotesis ke tiga $(\mathrm{H} 3)$ yang di bangun oleh peneliti menyebutkan bahwa pelimpahan 
wewenang tidak berpengaruh singnifikan terhadap kinerja Aparatur Pemerintah Daerah diterima.

3. Hasil pengujian ini didapati bahwa variabel pelimpahan berpengaruh terhadap kinerja Aparatur Pemerintah Daerah Kabupaten Batanghari dikarenakan nilai thitung $1.570<\mathrm{t}$-tabel 1.66025 . Hasil pengujian ini menginterpretasikan bahwa variabel Pelimpahan Wewenang Kinerja tidak berpengaruh terhadap Kinerja Aparatur Pemerintah Daerah Kabupaten Batanghari.

Pengaruh partisipasi X1, motivasi X2, Pelimpahan wewenang $(X 3)$ secara bersama mempengaruhi variabel Kinerja (Y) Kinerja Aparatur Pemerintah Daerah Kabupaten Batanghari

Hasil pengujian Uji $\mathrm{F}$ variabel partisipasi $\mathrm{X} 1$, motivasi X2, Pelimpahan wewenang (X3) secara bersama mempengaruhi variabel Kinerja (Y) terlihat dari tabel Anova Berdasarkan analisis statistik dalam penelitian ini, nilai F-hitung $4.789>$ Ftabel nilai 2.70. Artinya Partisivasi, Motivasi, Pelimpahan wewenang secara bersama-sama mempengaruhi Kinerja Aparatur Pemerintah Daerah Kabupaten Batanghari.

\section{SIMPULAN}

Berdasarkan hasil penelitian dan pembahasan maka penulis membuat empat kesimpulan sebagai berikut:

1. Terdapat pengaruh partisipasi terhadap kinerja Aparatur Pemerintahan Daerah Kabupaten Batanghari.

2. Tidak terdapat pengaruh motivasi terhadap kinerja Aparatur Pemerintahan Daerah Kabupaten Batanghari.

3. Tidak Terdapat pengaruh pelimpahan wewenang dalam penyusunan anggaran terhadap kinerja Aparatur Pemerintahan Daerah Kabupaten Batanghari.

4. Terdapat Pengaruh partisipasi, motivasi, Pelimpahan wewenang dalam penyusunan anggaran terhadap kinerja Aparatur Pemerintah Daerah Kabupaten Batanghari.

\section{DAFTAR PUSTAKA}

Abidin, M. Z. (2015). TINJAUAN ATAS KEBIJAKAN DANA INSENTIF DAERAH DALAM MENDUKUNG KINERJA PEMERINTAHAN PROVINSI DAN KESEJAHTERAAN MASYARAKAT. Civil Service Journal. https://jurnal.bkn.go.id/index.php/asn/article/view/ 56

Anwar, C., Sari, Y., \& Barusman, T. M. (2012). Analisis Penggunaan Anggaran Biaya Administrasi Umum Dan Efisiensi Terhadap Peningkatan Kinerja Supervisor (Studi Kasus pada PT. Lautan Teduh Interniaga Bandar Lampung). Jurnal Akuntansi Dan Keuangan, 3(1). https://doi.org/10.36448/jak.v3i1.225

Blunch, N. (2012). Introduction to Structural Equation Modelling Using SPSS and AMOS. In Introduction to Structural Equation Modelling Using SPSS and AMOS. https://doi.org/10.4135/9781446249345

Djaja, M. H. (2015). Analisis Efektifitas Penggunaan Anggaran Belanja Langsungterhadap Anggaran Berbasis Kinerja Pada Kantor Kecamatan Pamekasan. IQTISHADIA: Jurnal Ekonomi \& Perbankan Syariah, 2(1), 63. https://doi.org/10.19105/iqtishadia.v2i1.839

Dwi, F. S., Sri, R., \& WIRALESTARI, W. (2019). ... INTERVENTION (SURVEY ON OPD OF JAMBI CITY) PENGARUH PENERAPAN SAP, KOMPETENSI SDM DAN SPIP TERHADAP KUALITAS LAPORAN KEUANGAN .... Jurnal Akuntansi \& https://repository.unja.ac.id/18640/

FAUZAN, S. (2020). PENGARUH KUALITAS PENGANGGARAN DAN KOMPETENSI SUMBER DAYA MANUSIA BIDANG KEUANGAN TERHADAP KINERJA KEUANGAN SEKOLAH. Soedirman Economics Education Journal. http://jos.unsoed.ac.id/index.php/seej/article/view/ 3100

Galbraith, J. (n.d.). Designing complex organizations. Addison-Wesley Publishing Company 1973.

Giusti, G., Kustono, A. S., \& Effendi, R. (2018). Pengaruh Partisipasi Anggaran Terhadap Kinerja Manajerial dengan Komitmen Organisasi dan Motivasi Sebagai Variabel Intervening. E-Journal Ekonomi Bisnis Dan .... https://jurnal.unej.ac.id/index.php/eJEBAUJ/article/view/8646

Hairo, A. M., \& Martono, S. (2019). The Effect of Environment, Training, Motivation, and Satisfaction on Work Productivity. Management Analysis Journal. https://journal.unnes.ac.id/sju/index.php/maj/articl e/view/26390

Hansen, D. O. N. R. (1997). Hansen \& Mowen $2007-$ Managerial Accounting, $8 \mathrm{Ed}$.

Herlina, E., \& Lestari, M. N. (2021). PENGARUH KEJENUHAN KERJA DAN STRES KERJA TERHADAP KINERJA PEGAWAI (Suatu Studi Pada Pegawa Bagian Instalasi Gizi RSUD Kab. Ciamis). Business Management and .... https://jurnal.unigal.ac.id/index.php/bmej/article/v iew/4267

Hidayah, M., \& Haryono, A. T. (2015). Effect of Motivation And Managerial Ability to Performance Employee of PT. Star Alliance Intimates Semarang. Journal of Management. http://jurnal.unpand.ac.id/index.php/MS/article/vie $\mathrm{w} / 287$ 
Ho, R. (2006). Handbook of Univariate and Multivariate Data Analysis and Interpretation with SPSS.

Jak, S. (2015). Springer Briefs in Research Synthesis and Meta-Analytic. Meta-Analytic Structural Eqution modelling. www.springer.com/series/10240

Menpan. (2013). Evaluasi AKIP. 53(9), 1689-1699.

MenpanRB. (2012). Petunjuk Pelaksanaan Evaluasi Akuntabilitas Kinerja Instansi Pemerintah. menpan dan.

Menteri, dalam N. (2007). Perubahan atas peraturan Menteri dalam negeri nomor 13 tahun 2006 tentang pedoman pengelolaan keuangan daerah republik indonesia. 1-13.

Nazir, T., Khan, S. U. R., Shah, S. F. H., \& ... (2013). Impact of rewards and compensation on job satisfaction: Public and private universities of UK. In Middle-East Journal of .... academia.edu. https://www.academia.edu/download/31197225/n azir_et_al_MEJSR.PDF

Permenpan. (2014). Permenpan no 53 tahun 2014 tentang Juknis Perjanjian Kinerja, Pelaporan Kinerja dan Tata Cara Reviu atas LKj.

Prasetyo, A. W. (2019). Telaah Pengembangan Kompetensi Aparatur Pemerintah Desa. Journal of Public Administration and Local .... https://jurnal.untidar.ac.id/index.php/publicadmini s/article/view/1969

Ridwan, S., \& Anik, H. (2020). THE EFFECT OF ORGANIZATIONAL CULTURE, NON FINANCIAL COMPENSATION AND JOB SATISFACTION ON ORGANIZATIONAL COMMITMENTS IN THE .... ... International Journal of Education Management .... https://dinastipub.org/DIJEMSS/article/view/473

Syachbrani, W., \& Baharuddin, S. M. (2019). Implementasi Audit Operasional dalam Prinsip Transparansi dan Akuntabilitas pada Kantor Kelurahan Baurung Kecamatan Banggae Timur Kabupaten Majene. In ... Journal for Research in ... ojs.stiem-bongaya.ac.id. https://ojs.stiembongaya.ac.id/index.php/BJRM/article/download/ $181 / 126$

Thakkar, J. J. (2013). Structural Equation Modelling. https://doi.org/10.1108/s14793512(2013)0000027012 